\title{
In memoriam: Melvin J. Hinich, 1939-2010
}

\author{
Peter Ordeshook • Michael Munger • Tse-min Lin • \\ Bryan Jones
}

Received: 4 October 2010 / Accepted: 18 November 2010 / Published online: 2 December 2010

(C) Springer Science+Business Media, LLC 2010

Melvin J. Hinich achieved an international reputation in four academic disciplines: economics, engineering, political science, and statistics. He was a member of the Public Choice Society almost from its founding, and published a paper (with Otto Davis) in the very first year the journal was published under its present name. ${ }^{1}$ He was later named a Fellow of the Society, in 1988, and served as its $16^{\text {th }}$ President, from 1992 to 1994 . He continued to serve as an active member of the journal's Editorial Board until his death in September 2010.

He published original and path-breaking contributions in seven books and more than 400 journal articles, ranging over forty years, with an endless energy for work and a childlike curiosity about the science of almost everything. Hinich's scholarship blended technical virtuosity, theoretical depth, interdisciplinary sweep, and a keen eye for the main chance in terms of substantive importance. But Mel was not simply a bright but easily distracted scholar with many interests. Rather, he was a scientist, a person who found most problems interesting, and he was capable of making connections across fields because so many problems share a deep mathematical structure.

Mel received a BS and MS in Mathematics from the Carnegie Institute of Technology in 1959 and 1960, respectively. He earned his Ph.D. in Statistics from Stanford University in 1963, working under Dr. Herman Chernoff. His thesis project involved the problem of estimating the properties of a recurring but unknown waveform in Gaussian data, and proved

\footnotetext{
${ }^{1}$ Davis and Hinich (1968). The journal was founded as Papers in Non-Market Decision-Making by Gordon Tullock in 1966, and the name was changed to Public Choice in 1968.

P. Ordeshook

California Institute of Technology, Pasadena, CA, USA

M. Munger (凶)

Duke University, Durham, NC, USA

e-mail: munger@duke.edu

T.-m. Lin · B. Jones

University of Texas Austin, Austin, TX, USA
} 
useful enough to have the central theoretical result serve as the basis for a variety of civilian and military applications in signal processing. Professor Chernoff, as Mel told the story, was initially skeptical of the validity of Mel's intuition about the main theorem to be proved. To be fair, it is possible that Mel was a little too self-confident that his intuition was correct, given his status then as a graduate student. Chernoff, perhaps to teach Mel a lesson in humility, worked out a detailed counterproof. But when Mel arrived at the office the next morning, a rumpled and unshaven Chernoff tossed a sheaf of papers on the desk and said, "There, you lucky (he did not say "fellow"), there's your thesis." Instead of a counterexample, Chernoff had spent a sleepless night proving that Hinich's intuition, though not obvious, was correct.

Hinich began his academic career with the Graduate School of Industrial Administration at Carnegie Institute of Technology in September 1963. He then circulated between academic teaching and research posts and stints in settings where he could apply his knowledge to industrial and governmental uses. He held positions at the Bell Laboratories, the Columbia University-Hudson Laboratories, the Center for Naval Analyses, and the Naval Coastal Systems Center. His academic appointments have been at Carnegie Mellon University in the Graduate School of Industrial Administration and the School of Urban and Public Affairs and in the Department of Statistics. He moved to Virginia Polytechnic Institute as Professor of Economics in 1974 and on to the University of Texas as Professor of Government and Economics in 1983. He also served as Research Professor in the Applied Research Laboratories at UT-Austin.

Mel's impact is easily illustrated both quantitatively and qualitatively. Numerically, his work has been cited more than 5,000 times in the professional literature, with 20 different papers and books in economics, political science, signal processing and statistics all having received more than 100 references. The point is that no one paper, and in fact no one disciplinary contribution, are the "main" result. Mel's contributions were broad and deep.

Qualitatively, Mel's work was recognized by his peers and colleagues, by naming him to numerous honors and memberships in honorary societies. He was named Fellow of the Institute of Mathematical Statistics in 1973, appointed the Sherman-Fairchild Distinguished Scholar at the California Institute of Technology in 1975, named a Fellow of the Public Choice Society in 1988, elected President of that Society in 1992, and named a Fellow of the American Statistical Association in 2002. Most recently, in 2008, Mel was named one of the 21 original Fellows of the Society for Political Methodology. Hinich still ranks among the 100 most influential political scientists on a recently compiled list ${ }^{1}$ that includes all political scientists in US research universities since the 1950s.

\section{Scholarly works}

Mel's scientific contributions were so sweeping that we can only summarize them briefly. Given the subject of this journal, and because Mel spent most of the last 30 years of his professional life in an academic department of government, we will focus most fully on his considerable contributions to political science. Perhaps no intellectual movement has had greater impact in political science in the last quarter century than work that employs public choice-style game theory and microeconomic reasoning to build formal models of political decision making.

Mel's seminal contribution, in collaboration with Otto A. Davis was the formalization of the spatial theory of voting and elections. Although the perspectives of that model were

\footnotetext{
${ }^{1}$ Grofman and Matsuoka (2007).
} 
qualitatively identified by earlier researchers, it was Mel's conviction that if a model or idea was to yield scientifically testable propositions, it required formalization-and in the early 1960s it was Mel who provided that foundation. Today, thanks to that effort, spatial voting choice theory occupies a role in political science that is as central as consumer choice is in economics.

Mel, however, didn't formalize for the sake of displaying his considerable mathematical talents, and what made him unusual was his insistence on staying close to the data in the modeling exercises he engaged in. As the methods field splintered into "theory modelers" and "statistical modelers," Mel resolutely bridged the gap and continued to use formal models as a way of understanding data, and the underlying processes of politics. As a consequence his work exhibited careful attention to the methods of statistical analysis and considerable deftness in applying these skills to the analysis of empirical data. In a field often admired for its abstract models and arcane mathematics but condemned for its failure to connect to the real world, Mel had a special talent for linking theories to data. He was not only a pioneer of the spatial choice revolution; he was until the time of his death one of the most productive and innovative members of the field.

\section{The spatial theory of electoral competition}

Hinich was not merely one of the central figures in the early development of "spatial theory," he was the central figure, the nexus of all important early collaborations. Spatial theory is a predictive and descriptive model based on the premise that the actors being studied prefer policies "closer" to their own goals and principles. The most significant contribution to the progress of a science of politics has been the capacity of spatial theory to capture the primary dimensions of conflict dividing political elites, including interest groups and parties, as well as mass political actors. Mel's initial contribution here was the construction of a mathematically rigorous model with clear empirical implications. More importantly, Mel did not see that initial contribution as an end point of research, but only a beginning. Mel had little interest in producing an endless series of disconnected mathematically elegant papers that lengthened one's vita, but offered nothing but empirically vacuous technical reformulations, doing little to advance his clear understanding of science. His core motivation was to develop a science of politics and to give its study an empirically connected theoretically grounded base. Thus, while his ideas build on those of William Riker (1986), who posited that the addition of "new" dimensions was a key part of political strategy, Hinich argued that the very nature of the "space" of politics itself was contingent, an idea that had also been suggested by Ordeshook's (1976) idea of a "basic space". 2

As mentioned above, in 1963 Hinich began a fruitful collaboration with Otto Davis, an eminent economist, on the development of the multidimensional spatial theory of the electoral process. This theory uses a conception of voter utility that is proportional to the "distance" between the candidate or party being considered, and the voter's most preferred set of policies. The Davis-Hinich model makes the concept of distance mathematically precise, by defining the weighted Euclidean distance metric and allowing for both differences in salience and for connected or "nonseparable" preferences on different dimensions. In later

\footnotetext{
${ }^{2}$ An interesting and personal history of this idea was written by Keith Poole, a long-time friend of Mel Hinich. See Poole (2008).
} 
work, the nature of the dimensions themselves was extended to take into account the (empirically demonstrable) latency of ideological or values-based dimensions that are linked, both in the political rhetoric of campaigns and in voters' minds, to real political issues.

Although spatial theory has its roots in the early writings of Anthony Downs (1957) and Duncan Black (1958), it was really Hinich, with two different coauthors, Otto Davis and Peter Ordeshook, who developed the formal model on which spatial theory today rests. The main papers (Davis and Hinich 1966, 1967, 1968, 1971; Hinich and Ordeshook 1969, 1970, 1971; and Davis et al. 1970) were all published by 1971. By inserting a matrix of weights into the Downsian model, and by demonstrating the ability of the extended model to test much more general claims about politics, spatial theory was given a much needed generality and a mathematical life. More importantly, by allowing the representation of much more general and at the same time verisimilous sets of preferences, Davis, Hinich, and Ordeshook transformed the model from a curiosity into a practical and powerful modeling tool.

In forty years, what Hinich and his collaborators started has now developed into a vast system of political knowledge consisting of numerous axioms and theorems woven together by mathematical reasoning. To the extent that elections are crucial to democratic politics, the spatial theory of elections elevates the study of politics to a theoretical science built upon the solid foundation of mathematics. Many political scientists would argue that the publication of Davis et al. (1970), "An Expository Development of a Mathematical Model of the Electoral Process", like the publication of The American Voter (1960), was a defining moment for contemporary political science. It was a tour de force statement of the state of the field as of 1970 - and was required reading for many years afterward, not replaced until Enelow and Hinich's Spatial Theory of Voting in 1984, which has itself become a central work in the field, attracting well over 1,000 citations. Hinich's collaboration with Enelow produced two books and more than 15 widely referenced articles, work that still represents the core of empirical spatial theory in political science.

What is critical here to note is that all of this research not only carries the common name of "Hinich" but that it is also collaborative. Mel was not engaged on some academic ego trip. His views of science included the argument that the most fruitful research requires collaborative efforts wherein coauthors test each other's ideas while contributing new ones in a context wherein true scientific advances occur as the product of the give and take of intellectual argument. And Mel was a scientist! For Mel, though, a true scientist is not one who spins off abstract mathematical models about, as he often liked to say, planet X. A true scientist is one who attempts to understand real-world empirical phenomena. Unsurprisingly, then, his work in spatial theory led directly to issues of how to detect spatial structure in voting data through statistical estimation and inference. In collaboration with one of his statistics Ph.D. students at the Department of Statistics at Carnegie Mellon, Lawrence Cahoon, Mel developed in 1978 a metric multidimensional scaling methodology that is based on the parametric weighted utility model for voting choice.

This methodology was further developed by Hinich over many years and is now called the Cahoon-Hinich MAP Method. The method is complex, but can be briefly described as follows. The MAP program takes information about voter preferences (thermometer scores) and constructs a latent "space," where the number and location of dimensions is determined by the data themselves. The output of the estimation is analogous to the results of the PooleRosenthal "space" of political conflict in the Congress, in the sense that it estimates the contours of the space and the location of the political actors in that space. The difference is that the MAP program uses stated preferences, rather than actions (for Poole and Rosenthal, voting), and the actors for whom the model is designed are citizen-voters, rather than 
elites or members of the legislature. ${ }^{3}$ But one feature of Cahoon-Hinich warrants emphasis. Multidimensional metric scaling of attitudes has, of course, a long history beginning with the formulation of the Guttman scale in The American Soldier. The Cahoon-Hinich methodology is a statistical method-one that provides statistical estimates of parameters along with the means for testing their statistical significance. Once again, as a scientist, Mel saw methodologies not as a path to producing "numbers" but as a route to testing hypotheses.

Throughout the process, Mel thought of any idea or development as nothing more or less than a place to stand to develop more insights, theories, and tests of theories. His work was a springboard for Jones's development of a spatial approach to agenda-setting. The key feature of this work (Jones 1995) is that salience measures (the elements on the main diagonal of the A matrix) could vary over time, shifting preference orderings in unexpected ways. When Jones tentatively presented his perhaps harebrained idea at a seminar run by Mel at the University of Texas in the mid-1990s, Mel, far from being critical, was enthusiasticappreciating the underlying idea as an explanation, even though it could not be used in an ex ante predictive model. As we noted above, Mel's scientific interests came first, and he had little attachment to ideas simply for ego's sake. His goal was to understand the world, and he loved good ideas and connections, no matter how ill-formed at the first.

In fact, for those interested in the genesis of spatial theory as we know it today, a brief diversion and connection is useful. Mel's early work as an assistant professor addressed a problem that the Defense Department otherwise found intractable. Briefly, the U.S. Navy had to decide between two alternative ASW (anti-submarine warfare) systems for detecting and locating enemy submarines. One alternative was a system of sonar devices scattered about the ocean that provided range only data (distance from a detected object). The second alternative provides both direction and range data. The advantage of the first was costeach unit was far cheaper than that of the second alternative and, thus, many more units were feasible with the first. At issue, though, was the capabilities of each system. Such a problem, of course, presented daunting statistical and modeling problems. The acoustic properties of the ocean are confounded by innumerable non-linearities, thereby rendering any simplistic approach worthless.

But for a statistician of Mel's talents, the problem was like red meat before a hungry lion. At the same time, though, Mel, in his inimitable style at Carnegie, would hold conversations with anyone about anything provided that there was intellectual content to the conversation. And it was in some of those lunchtime conversations, with Otto Davis, that Mel saw the connection between his work in ASW and the problem of statistically estimating the positions of candidates in a multidimensional issue space when surveys provided "range only" data in the form of thermometer scores. The rest, of course, is history, though once again we need to appreciate that Mel didn't simply apply some preexisting statistical model to politics as many in the discipline are wont to do, but instead developed a substantively grounded general theory of elections.

Later, Mel helped develop the Cahoon-Hinich methodology of spatial analysis, a large additional step in estimating position using "range only" data. This work makes it possible for the spatial theory of elections to be empirically studied and tested in a wide variety of contexts. Since the publication of The Spatial Theory of Voting (Enelow and Hinich

\footnotetext{
${ }^{3}$ Hinich, Poole, and Rosenthal were long-time colleagues and friends at Carnegie-Mellon, and Keith and Howard certainly made a number of important contributions, in conversations and at conferences, to the conception of an ideological "space" that took such a central place in Mel's thought and writing. And Poole and Rosenthal also wrote their own version of a theory of ideological organization of political competition in their book (Poole and Rosenthal 1997), which has since taken a justifiably central place in our understanding of legislatures.
} 
1984), which documents the methodology in detail, the Cahoon-Hinich methodology has been applied to elections in many countries, including Chile, Germany, Korea, Russia, Taiwan, Turkey, Ukraine, and the United States. His collaboration with Ordeshook in Ukraine, for example, not only illustrates his commitment to empirical research and the value of the Cahoon-Hinich methodology to understanding the emergence of political party structures in a nascent democracy, but also Mel's willingness-even fervent desire-to maintain collaborative relationships through the decades.

Mel loved working with coauthors. In addition to Davis and Ordeshook in the first decade of Public Choice, Hinich began a long and fruitful collaboration with James Enelow in 1978 on both theoretical expansions of spatial theory and on using the Cahoon-Hinich MAP program to estimate spatial maps of candidates in American politics using the thermometer scores from Inter-University Consortium for Political and Social Research (ICPSR) surveys. The collaboration produced the first book on the modern spatial theory of elections: The Spatial Theory of Voting (Enelow and Hinich 1984). Then they produced an edited volume on spatial theory: Advances in the Spatial Theory of Voting, J. Enelow and M.J. Hinich (eds.), Cambridge University Press (1990).

After Hinich moved to the University of Texas in the Department of Government, he began a collaboration with Michael Munger, an Assistant Professor in the department whose doctorate was in economics. Their extension of the spatial theory of elections resulted in several papers and three books: Ideology and the Theory of Political Choice, University of Michigan Press (1994), Analytical Politics, Cambridge University Press (1997), and Empirical Studies in Comparative Politics, Kluwer Academic Publishers (1999).

There was an additional strand of research in which Mel had a seminal role. In 1977 Hinich published a paper in the Journal of Economic Theory that introduced a model of probabilistic voting. The model has both theoretical and empirical implications, but one of the most interesting is that it illustrates how democratic systems can be stable and avoid the cycling that the open agendas spatial theory predicts. This model was an outgrowth of a simpler probabilistic voting model that Hinich had developed with Peter Ordeshook and John Ledyard several years before. This paper is still widely cited by political economy scholars.

Hinich used this probabilistic voting theory to develop, along with Munger, a type of general equilibrium model in their 1994 book on political ideology. This book unites three streams of thought in Hinich's work, because it is based on the idea of latent, constructed dimension, but rests on a model of campaign contributions as the vector through which elites can influence politics. The third theoretical connection with Mel's earlier work is equilibrium concept, based on probabilistic voting. By uniting these three separate bodies of theory, the book illustrates the predictions of a more general model of political competition, where elites are an important moving part, but in which the social construction of political belief, and rhetoric, plays a key role.

Hinich supervised a total of $16 \mathrm{Ph} . \mathrm{D}$. students at Texas, several of whom have contributed to the theoretical and empirical development of spatial theory. His most recent, and last, student was Chih-Cheng (Almond) Meng, who finished his dissertation in the spring of 2010 .

\section{Work outside political science}

In addition to his work in political science on spatial theory and estimation, Mel has a very serious presence in the statistical study of time series and non-linear dynamics. We will 
simply relay an anecdote. When Jones was head of Political Science at Texas A\&M, he got a call from Manny Parzen, the distinguished statistician. He said the Statistics Department was inviting Mel over to give a presentation on his time series work, and wanted to know if Political Science wanted to invite him for a talk. Jones said sure, that he had meant to do that beforehand. "Bryan, does Mel have a reputation in political science?" Manny asked. He was quite surprised to hear that the answer was yes.

In 1969 Hinich published a paper in the Reviews of Geophysics that became highly influential in that field. The results in this paper showed how to use the rediscovered digital method of computing a discrete Fourier transform to estimate a power spectrum, a cross spectrum, and a bispectrum along with the large sample statistical properties of the estimated functions. The bispectrum was developed by Russian mathematical statisticians to study nonlinear mechanisms. Later bispectral analysis sans statistical properties became an integral part of astrophysics.

Early in his career at Carnegie Mellon Hinich wrote several papers on detecting a shift in the mean of a time series. Those early papers were broadly cited in the 1960s and 1970s but the so-called "change point" field in time series became a veritable industry around 1975. Mel's straightforward, but important, ideas about stationarity and regime shift in data lie at the core of many important results in time series, even today, because of Mel's continued dedication to understanding the problem. In fact, twenty years after his first work in time series, just one of his papers (Hinich 1982, "Testing for Gaussianity and linearity of a stationary time series") has been cited nearly five hundred times in the formal statistics literature.

\section{Personal reflections}

Mel's commitment to science, and his appetite for collaborators who could learn from him and teach, is the central theme of his scholarly life. In 1965 Bill Riker handed a first year Rochester graduate student a paper written by two people he'd not heard of - Otto Davis and Melvin Hinich. The student, sadly, knew little linear algebra and the Davis-Hinich paper was as dense with that branch of mathematics as anything he'd seen. So he set out to teach himself by working through the essay line by line, Greek symbol by Greek symbol—until he came to a $2 \frac{1}{2}$ page proof he couldn't comprehend. But he stuck with it and over a period of 2 or 3 weeks, worked out a shorter alternative proof. Satisfied with himself he set the paper aside. A few months later Riker invited Davis and Hinich to the Rochester campus to give their paper. Amazingly, after Davis had presented the main ideas, someone in the audience asked about that very theorem, whereupon Mel stepped to the blackboard and filled it thoroughly. Upon the conclusion of the seminar, the graduate student approached "Professor Hinich" and asked if he could show him his alternative proof to see if there was a flaw in the argument.

After writing it on the blackboard, Mel nodded his head and said "yes, that's better than mine," after which the student went back to doing whatever graduate students do. To make an already long story short, three years later when the student entered the job market, he immediately learned he had a "wired" offer from Carnegie Mellon. Turns out, Mel remembered that Rochester seminar, remembered that student and his assessment then that "we can do science together," and ensured that Carnegie hired Peter Ordeshook when his PhD work was done.

Since the mid-1990s, Jones would sometimes drop by Mel's house with a six-pack of beer, or would drive with Mel to a watering hole, which always led to a two or three hour discussion of all sorts of fascinating topics. That became more regular (but not regular enough) 
when Jones joined the Texas department in 2008. The week before he died, and right after Mel had returned from Italy, Australia and Chile where he was working with collaborators, the two dropped by Jorge's restaurant in Austin for some drinks and two hours of conversation. Those who know Mel will appreciate how such affairs could decline into the depths of blackness. But they invariably also soared intellectually; Jones always felt rejuvenated from these events.

On the day before he died, Mel called up one of the authors of this paper (Munger) to talk about a new chapter for the revised edition of Analytical Politics (Cambridge University Press). That revised edition should be finished soon, and published at the end of 2011, a posthumous testimony to Melvin Hinich's continuing influence and focus on the development of a science of politics.

\section{References}

Black, D. (1958). The theory of committees and elections. New York: Cambridge University Press.

Davis, O., \& Hinich, M. (1966). A mathematical model of policy formation in a democratic society. In J. Bernd (Ed.), Mathematical applications in political science II. Monograph, Arnold Foundation Monographs (pp. 175-208). Dallas: Southern Methodist University Press.

Davis, O., \& Hinich, M. (1967). Some results related to a mathematical model of policy formation in a democratic society. In J. Bernd (Ed.), Mathematical applications in political science III (pp. 14-38). Charlottesville: University Press of Virginia.

Davis, O., \& Hinich, M. (1968). On the power and importance of the mean preference in a mathematical model of democratic choice. Public Choice, 5, 59-72.

Davis, O., \& Hinich, M. (1971). Some extensions to a mathematical model of democratic choice. In B. Lieberman (Ed.), Social choice (pp. 323-347). New York: Gordon and Breach.

Davis, O., Hinich, M., \& Ordeshook, P. (1970). An expository development of a mathematical model of the electoral process. American Political Science Review, 64(2), 426-448.

Downs, A. (1957). An economic theory of democracy. Chicago: Addison-Wesley.

Enelow, J., \& Hinich, M. (1984). The spatial theory of voting: an introduction. Cambridge: Cambridge University Press.

Enelow, J., \& Hinich, M. (Eds.) (1990). Advances in the spatial theory of voting. Cambridge: Cambridge University Press.

Grofman, B., \& Matsuoka, N. (2007). The political science 400. PS: Political Science and Politics, 40, 133145.

Hinich, M. J. (1982). Testing for Gaussianity and linearity of a stationary time series. Journal of Time Series Analysis, 3, 169-176.

Hinich, M., \& Munger, M. (1994). Ideology and the theory of political choice. Ann Arbor: University of Michigan Press.

Hinich, M., \& Munger, M. (1997). Analytical politics. Cambridge: Cambridge University Press.

Hinich, M., \& Ordeshook, P. (1969). Abstentions and equilibrium in the electoral process. Public Choice, 7 , 81-106.

Hinich, M., \& Ordeshook, P. (1970). Plurality maximization: a spatial analysis with variable participation. American Political Science Review, 64(3), 772-791.

Hinich, M., \& Ordeshook, P. (1971). Social welfare and electoral competition in democratic societies. Public Choice, 11, 73-83.

Jones, B. D. (1995). Reconceiving decision-making in democratic politics: attention, choice, and public policy. Chicago: University of Chicago Press.

Ordeshook, P. C. (1976). The spatial theory of elections: a review and a critique. In I. Budge, I. Crewe, \& D. Farlie (Eds.) Party identification and beyond. New York: Wiley.

Poole, K. T. (2008). Nominate: A short intellectual history. Available at SSRN: http://ssrn.com/ abstract $=1154153$.

Poole, K., \& Rosenthal, H. (1997). Congress: a political-economic history of roll call voting. New York: Oxford University Press.

Riker, W. (1986). The art of political manipulation. New Haven: Yale University Press. 